\title{
Hiwi facilitates chemoresistance as a cancer stem cell marker in cervical cancer
}

\author{
WEI LIU $^{1 *}$, QING GAO $^{1 *}$, KUNLUN CHEN $^{2}$, XIANG XUE $^{1}, \mathrm{MU} \mathrm{LI}^{1}$,

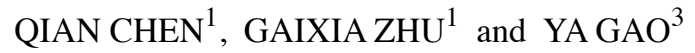 \\ Departments of ${ }^{1}$ Obstetrics and Gynecology, ${ }^{2}$ General Surgery and ${ }^{3}$ Pediatric Surgery, \\ The Second Affiliated Hospital, Medical School of Xi'an Jiaotong University, Xi'an, Shaanxi, P.R. China
}

Received May 21, 2014; Accepted July 8, 2014

DOI: $10.3892 /$ or.2014.3401

\begin{abstract}
Hiwi, also named PiwiL1, is a human homologue of the Piwi family which is associated with stem cells and is overexpressed in several types of cancers. In the present study, we aimed to investigate the role of Hiwi in cervical carcinogenesis. Immunochemical analysis showed a significantly higher frequency of Hiwi staining in high-grade squamous intraepithelial lesions (HSILs) and cervical cancer tissues when comparing with the frequency in normal cervices. Particularly, Hiwi staining was restricted to basal cells of the normal cervix and was associated with the progression of cervical cancer and chemotherapy resistance. We further found that ectopic Hiwi increased the chemical resistance in SiHa cells, and silencing of Hiwi in HeLa cells decreased the cell viability. In addition, as a cancer stem cell marker, Hiwi promoted the tumorsphere formation in vitro and tumorigenicity in vivo and elevated the expression of several stem cell self-renewal-associated transcription factors, in spite of inhibited the proliferation. These results suggest that Hiwi may participate in the carcinogenesis of cervical cancer and may be a potential therapeutic target molecule for cervical cancers.
\end{abstract}

\section{Introduction}

Cervical cancer is the third most common malignancy in women of reproductive age, and the incidence just succeeds that of breast cancer and colorectal cancer (1). In the past few decades, the cervical cancer-related morbidity and mortality in young adult women have increased. There are many factors which contribute to cervical carcinogenesis. The relationship between cervical cancer and persistent infection with HPV has been well established $(2,3)$. In recent years, emerging evidence

Correspondence to: Professor Ya Gao, Department of Pediatric Surgery, The Second Affiliated Hospital, Medical School of Xi'an Jiaotong University, Xi'an, Shaanxi, P.R. China

E-mail: gaoyaandliuwei@163.com

*Contributed equally

Key words: cervical cancer, Hiwi, cancer stem cell, chemoresistance suggests that cancer stem cells (CSCs) are a rare group of undifferentiated tumorigenic cells which are considered to be a renewable source of tumor cells and a source of drug resistance leading to tumor recurrence, metastasis and tumor progression $(4,5)$. Understanding the molecular mechanisms governing the initiation, progression and metastasis of cervical cancer are important for the prevention, detection and treatment of this prevailing disease.

Hiwi, a human member of the piwi family, maps to chromosome $12 \mathrm{q} 24.33$, and belongs to the piwi-domain proteins, which are components of ribonucleoprotein complexes. Hiwi plays an important role in stem cell self-renewal, gametogenesis, RNA silencing and translational regulation $(6,7)$. Expression of Hiwi has been found dysregulated in pancreatic carcinoma, seminomas, gastric carcinomas and soft-tissue sarcoma, and is described as an indicator of poor prognosis (8-12). Moreover, recent data suggest that Hiwi is required to maintain the stemness of hematopoietic stem cells (13). Thus, it has been proposed that Hiwi is a key regulator in the maintenance of cancer stem cell populations as well $(8,14)$.

In the present study, we examined the expression of Hiwi in cervical cancer to investigate the relationship between the deregulation of Hiwi expresion and cervical carcinogenesis, and then provide a necessary experimental and theoretical basis for the diagnosis and therapeutics of cervical cancer.

\section{Materials and methods}

Ethics statement. Female BALB/c nude mice (4-6-weeks old) were supplied by the Experimental Animal Center of Xi'an Jiaotong University, China. This study was carried out in accordance with the recommended guidelines for the care and use of laboratory animals issued by the Chinese Council on Animal Research. The protocol was approved by the Ethics Committee of Xi'an Jiaotong University.

Cell lines and cell culture. Human cervical cancer cell lines HeLa, SiHa and C33A used in this study were purchased from the American Type Culture Collection (ATCC; Manassas, VA, USA) and were cultured in Dulbecco's modified Eagle's medium (DMEM) (Sigma, St. Louis, MO, USA) supplemented with $10 \%$ fetal bovine serum (FBS) and maintaining at $37^{\circ} \mathrm{C}$ in an atmosphere containing $5 \% \mathrm{CO}_{2}$. 
Tissue collection. All of the archived formalin-fixed, paraffin-embedded tissue specimens were collected at the Second Hospital of Xi'an Jiaotong University (15). Before the collection of these clinical materials, all participating patients provided written informed consent. Histopathologic diagnosis and malignant classification were determined by 2 pathologists in a blinded manner and were based on the International Federation of Gynecology and Obstetrics classification system.

Immunohistochemistry (IHC) and immunocytochemistry (ICC). Slides were prepared from formalin-fixed and paraffin-embedded tissues and were stained for Hiwi. A standard immunostaining procedure was performed using the anti-Hiwi antibody (1:100; Santa Cruz Biotechnology, Santa Cruz, CA, USA). Briefly, sections were successively deparaffinized and rehydrated, followed by treatment with $10 \mathrm{mM}$ sodium citrate buffer ( $\mathrm{pH}$ 6.0) in a steam pressure cooker to retrieve the endogenous antigen, and treated with $3 \% \mathrm{H}_{2} \mathrm{O}_{2}$, and incubated with the primary antibody overnight at $4^{\circ} \mathrm{C}$. Then the sections were incubated with biotinylated secondary antibody for $30 \mathrm{~min}$ at room temperature, followed by diaminobenzidine development. All slides were examined under an Olympus-CX31 microscope (Olympus, Tokyo, Japan).

For detection of the expression of Hiwi in cells, the cells were seeded on coverslips for $48 \mathrm{~h}$, fixed with $4 \%$ paraformaldehyde for $30 \mathrm{~min}$, followed by $0.3 \%$ Triton X-100 permeabilization for $20 \mathrm{~min}$ at room temperature. Then immunohistochemistry was carried out as described above.

Immunohistochemical results of Hiwi expression in the cervical tissues were evaluated by 3 investigators independently and scoring was determined by the percentage of Hiwi-positive cells (1, $0-25 \%$ positive cells; $2,26-50 \%$ positive cells; $3,>50 \%$ positive cells) and the staining intensity $(0$, no staining; 1 , weak staining; 2 , moderate staining; 3 , strong staining).

Western blot analysis. Cells were lysed with ice-cold lysis buffer with a cocktail of protease and phosphatase inhibitors (Complete Mini; Roche Diagnostics, Branchburg, NJ, USA). Protein samples ( $20 \mu \mathrm{g}$ ) underwent electrophoresis on $10 \%$ sodium dodecyl sulfate polyacrylamide gel electrophoresis (SDS-PAGE) and were transferred onto polyvinylidene fluoride (PVDF) membranes. The membranes were blocked with 5\% fat-free milk in Tris-buffered saline and then incubated with anti-Hiwi or anti- $\beta$-actin (both from Santa Cruz Biotechnology, at 1:1,000) at $4^{\circ} \mathrm{C}$ overnight. After washing, the membranes were incubated with their associated horseradish peroxidase (HRP)-conjugated secondary antibody at the appropriate dilution and then visualized on X-ray film using an enhanced chemiluminescence reagent (Millipore, Billerica, MA, USA).

Array dataset. The 'Cervical cancer response to chemoradiotherapy' dataset (GDS3017) was downloaded from http://www. ncbi.nlm.nih.gov/sites/GDSbrowser?acc=GDS3017. This array is an analysis of 156 cervical cancer biopsy samples from patients receiving radiotherapy alone or radiotherapy plus concomitant chemotherapy with cisplatin (DDP). Results provide insight into the molecular mechanisms underlying the therapeutic response to DDP (16).
Plasmid construction and transfection. The human Hiwi CDS fragment was amplified by PCR and inserted into pIRSE2-eGFP to create the Hiwi overexpression vector (pIRSE2-eGFP-Hiwi) and the pIRES2-eGFP vector was used as a negative control. The plasmids expressing Hiwi-specific short hairpin RNA (pGPU6/GFP-shHiwi) were designed and purchased from GenePharm Company (Shanghai, China).

According to the manufacturer's instructions, the overexpression plasmids were transfected in the $\mathrm{SiHa}$ cells and silencing vectors were transfected in HeLa cells using Lipofectamine 2000 (Invitrogen, Carlsbad, CA, USA). After a 24-h transfection, cells were passaged into DMEM with $10 \%$ FBS in the presence of $1,000 \mu \mathrm{g} / \mathrm{ml}$ of G418 for 3 weeks. Individual drug-resistant clones were selected, pooled, expanded, and identified by western blotting.

Drug resistance and MTT assay. For drug resistance assays, cells were plated in 96-well plates at a density of $10^{4}$ cells/well and allowed to recover overnight before initiating drug treatments. The cells were exposed to various concentrations of cisplatin $(0,3,6,12,24$ or $48 \mu \mathrm{g} / \mathrm{ml}$ for SiHa and HeLa cells) for $24 \mathrm{~h}$, and cell viability was measured by MTT. In separate experiments, the cells were exposed to a constant concentration of cisplatin ( $3 \mu \mathrm{g} / \mathrm{ml}$ for SiHa and HeLa cells) for 24,48 or $72 \mathrm{~h}$, and cell viability was measured by MTT.

Following the manufacturer's instructions, $20 \mu 1$ of MTT (Sigma) solution $(5 \mathrm{mg} / \mathrm{ml})$ was added to $200 \mu 1$ of the culture medium. The plates were then incubated for $4 \mathrm{~h}$ at $37^{\circ} \mathrm{C}$. Following the incubation, $150 \mu \mathrm{l}$ dimethyl sulfoxide (DMSO; Sigma) was added to each well for dye extraction. The dark-blue crystals of MTT-formazan were thoroughly dissolved by shaking the plates at room temperature for $10 \mathrm{~min}$. Spectrometric absorbance at $490 \mathrm{~nm}$ was measured by a microplate reader (Bio-Rad, Hercules, CA, USA).

Cell cycle analysis. Cell cycle distribution was analyzed by propidium iodide (PI; Sigma) according to the manufacturer's instructions. Cells $\left(1 \times 10^{6}\right)$ were resuspended in PBS with $50 \mu \mathrm{g} / \mathrm{ml}$ PI and $10 \mu \mathrm{g} / \mathrm{ml}$ RNase A, following fixation with $70 \%$ ethanol. Cells were then detected for DNA content by flow cytometry and analyzed using ModFit ${ }^{\circledR}$ LT Software (Verity Software House Inc., Topsham, ME, USA).

Real-time PCR. Total RNA from the cells was extracted with TRIzol reagent (Invitrogen, Carlsbad, CA, USA) in accordance with the manufacturer's protocol. RNA concentration was determined for reverse transcription-PCR. Then total cDNA was used as a template for real-time PCR amplification using the SYBR-Green PCR kit (Takara, Japan). The cycle threshold value was determined as the point at which the fluorescence exceeded a preset limit determined by the instrument's software.

Tumorsphere formation assay. Cells were seeded in 6-well plates in $1 \mathrm{ml}$ serum-free DMEM/F12 medium supplemented with $20 \mathrm{ng} / \mathrm{ml}$ basic fibroblastic growth factor (bFGF; PeproTech Inc., Rocky Hill, NJ, USA), 20 ng/ml human recombinant epidermal growth factor (EGF; PeproTech), N2 and B27 (Invitrogen). Fresh medium $(0.5 \mathrm{ml})$ was added to each well every 3 days. The spheres were counted by two individuals in a blinded manner after 2-3-weeks of culture $(17,18)$. 
A
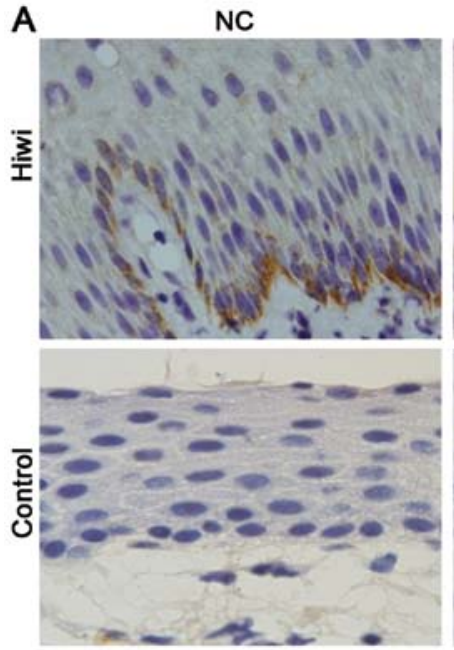

B

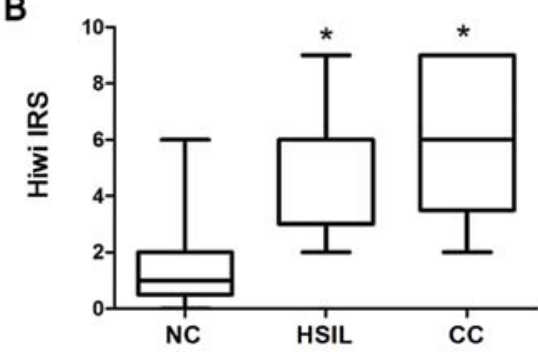

HSIL

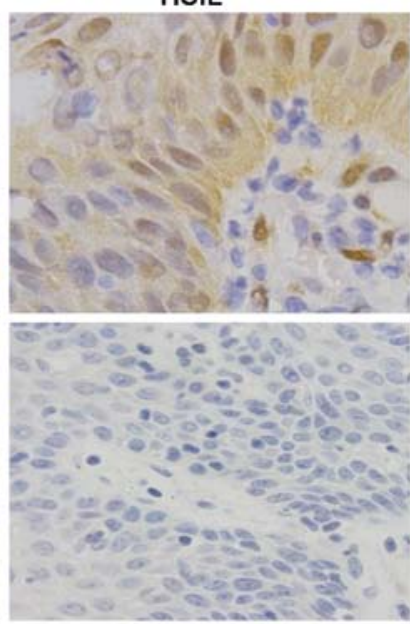

C
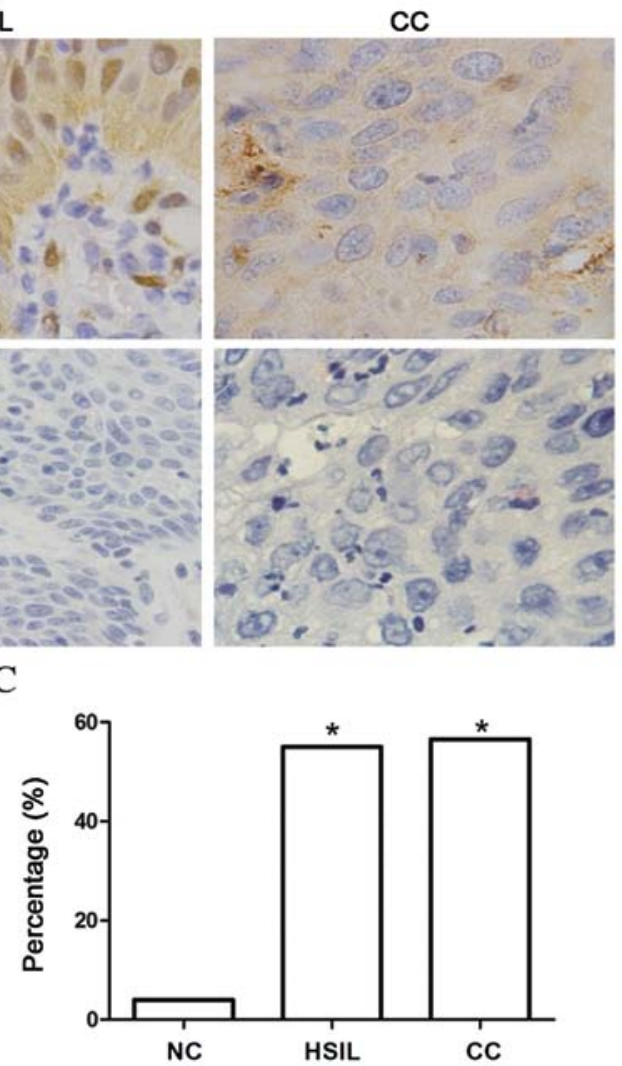

Figure 1. Expression of Hiwi in cervical tissues. (A) Immunohistochemical staining for Hiwi expression (magnification, x1,000) in normal cervical tissues (NC), high-grade squamous intraepithelial lesions (HSIL) and cervical cancers (CC). (B) Immunoreactivity scores (IRS) and (C) the positive percentage of Hiwi expression in NC, HSILs and CCs. ${ }^{*} \mathrm{P}<0.05$.

Tumor xenograft experiment. Cells $\left(10^{5}\right)$ were injected into the subcutaneous tissue in the dorsum of BALB/c nude mice. Three animals/group were used in each experiment. Engrafted mice were monitored twice per week by visual observation and palpation for the appearance of tumors over 12 weeks. The tumor volume (V) was determined by the length (a) and width (b) as $\mathrm{V}=\mathrm{ab}^{2} / 2$ (19).

Statistical analysis. All experiments were repeated at least 3 separate times. Data from all experiments were pooled, and the results were expressed as mean \pm SD. The t-test and log-rank test were performed with the Statistical Package for Social Sciences (SPSS) 16.0 statistical software (SPSS Inc., Chicago, IL, USA). P $<0.05$ was considered to indicate a statistically significant difference.

\section{Results}

Expression of Hiwi in the cervical tissues. We performed immunohistochemistry to detect the expression of Hiwi in 25 normal cervical tissues (NCs), 20 high-grade squamous intraepithelial lesions (HSILs) and 53 cervical cancer (CC) tissues. Hiwi was expressed in most cells of the CC and HSIL tissues but only in basal cells of the normal cervical epithelia (Fig. 1A). In addition, the IRS scores and the percentage of Hiwi-positive cases were markedly elevated in the HSILs and CCs when compared to these parameters in the NCs (Fig. 1B and $\mathrm{C}, \mathrm{P}<0.05$ ), showing a positive correlation with tumor progression.
Table I. Correlation between Hiwi expression and clinicopathologic parameters in patients with cervical cancer.

\begin{tabular}{lcccc}
\hline & & \multicolumn{2}{c}{ Hiwi IRS } & \\
\cline { 3 - 4 } Variables & $\begin{array}{c}\text { No. of } \\
\text { patients }\end{array}$ & Positive & $\%$ & P-value \\
\hline Age, years & & & & $>0.05$ \\
$<45$ & 18 & 12 & 66.67 & \\
$\geq 45$ & 35 & 18 & 51.43 & \\
Grade & & & & $>0.05$ \\
I & 7 & 4 & 57.14 & \\
II & 19 & 12 & 63.16 & \\
III & 27 & 14 & 51.85 & \\
Stage & & & & $<0.05$ \\
I & 16 & 5 & 31.25 & \\
II-III & 37 & 25 & 67.57 & \\
\hline
\end{tabular}

To further investigate the relationship between Hiwi expression and clinical disease progression, the results showed that the percentage of cases with positive Hiwi expression was higher in the advanced stage II-III cancers (25/37, 67.57\%) than the frequency of cases with positive expression in stage I cancers $(5 / 16,31.25 \%$ ) (Table I, $\mathrm{P}<0.05)$. Thus, we speculated that Hiwi expression is significantly correlated with the stage 

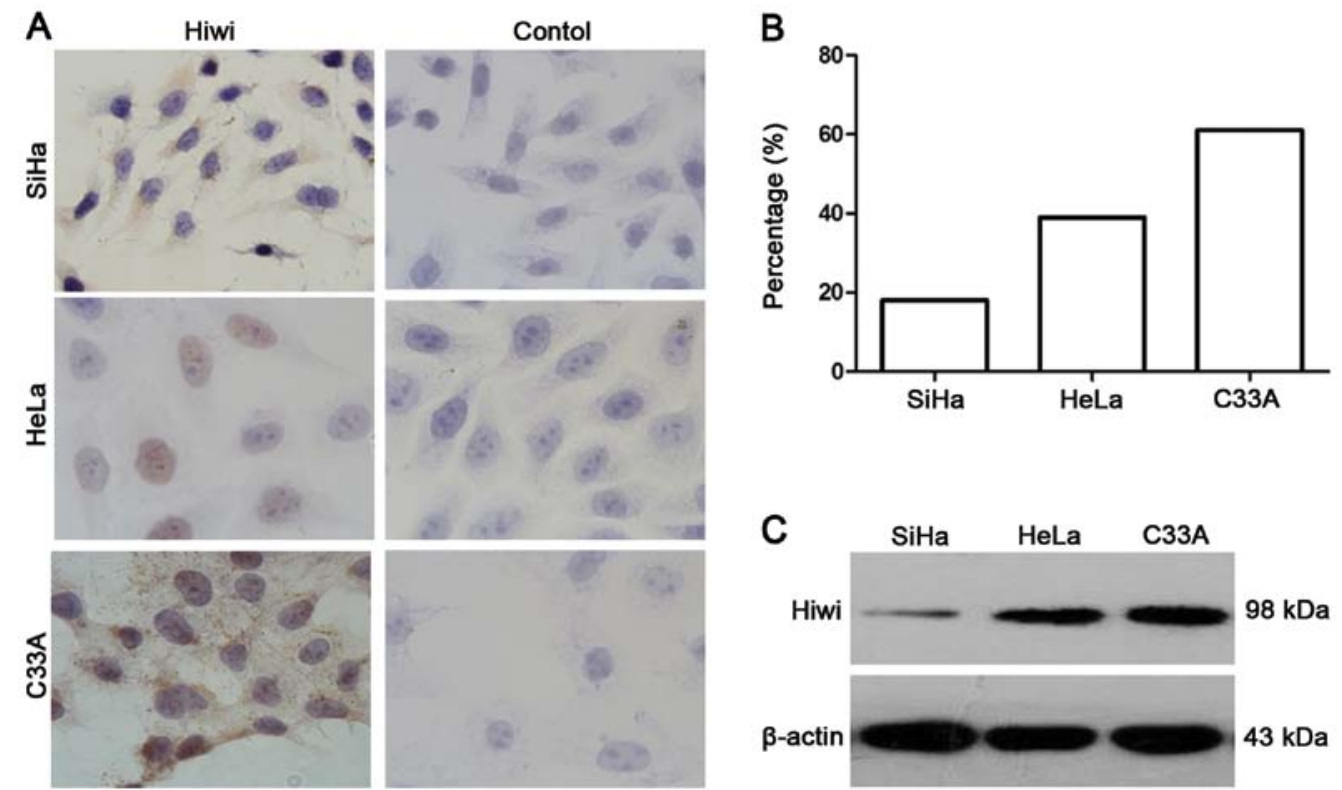

Figure 2. Expression of Hiwi in cervical cancer cell lines. (A) Immunocytochemical staining for Hiwi protein (magnification, x1,000) in SiHa, HeLa and C33A cell lines. (B) Positive percentage of Hiwi expression in cervical cancer cell lines. (C) Western blot analysis of the expression of Hiwi protein in cervical cancer cell lines.

A

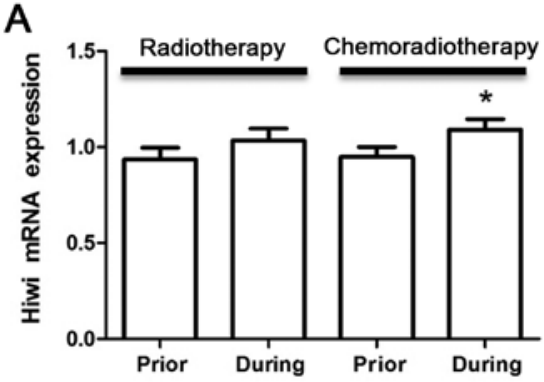

$c$

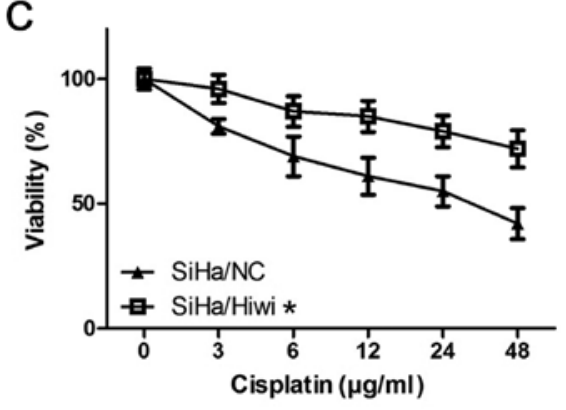

D

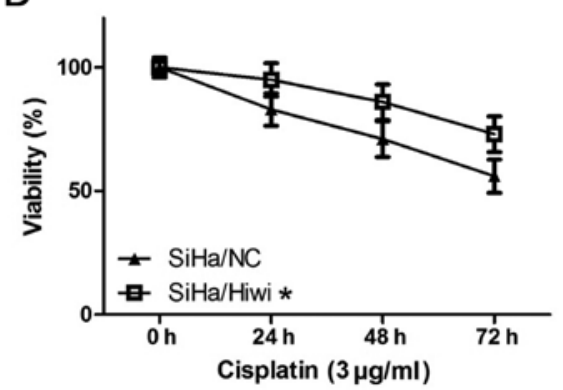

B
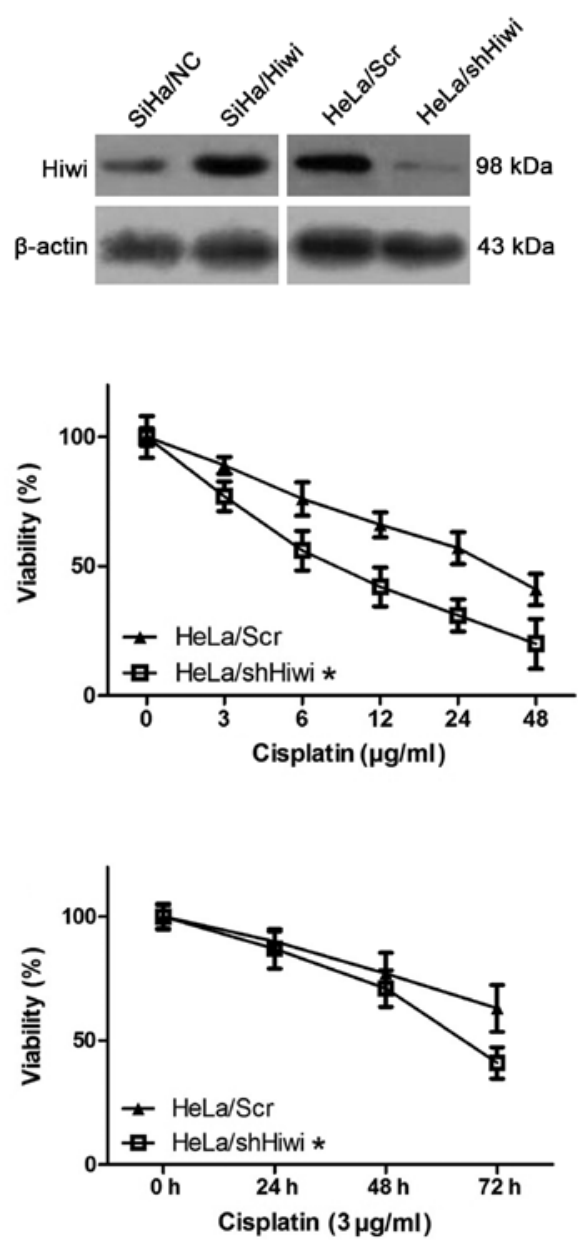

Figure 3. Hiwi faciliates resistance to cisplatin in cervical cancer. (A) Hiwi mRNA expression in relation to the cervical cancer response to radiotherapy or chemoradiotherapy. "P $<0.05$. (B) Confirmation of overexpression and silencing of Hiwi in SiHa and HeLa cells, respectively. (C) MTT assays of cell viability of $\mathrm{SiHa} / \mathrm{Hiwi}$ or $\mathrm{SiHa} / \mathrm{NC}$ cells (left) and $\mathrm{HeLa} / \mathrm{shHiwi}$ and $\mathrm{HeLa} / \mathrm{Scr}$ cells (right) after treatment with different concentrations of cisplatin for $24 \mathrm{~h}$. ${ }^{*} \mathrm{P}<0.05$.

(D) MTT assays for cell viability of $\mathrm{SiHa} / \mathrm{Hiwi}$ or $\mathrm{SiHa} / \mathrm{NC}$ cells (left) and HeLa/shHiwi and HeLa/Scr cells (right) after treatment with a constant dose (3 $\mu \mathrm{g} /$ $\mathrm{ml}$ ) of cisplatin for $0,24,48$ or $72 \mathrm{~h}$. ${ }^{*} \mathrm{P}<0.05$. 
A

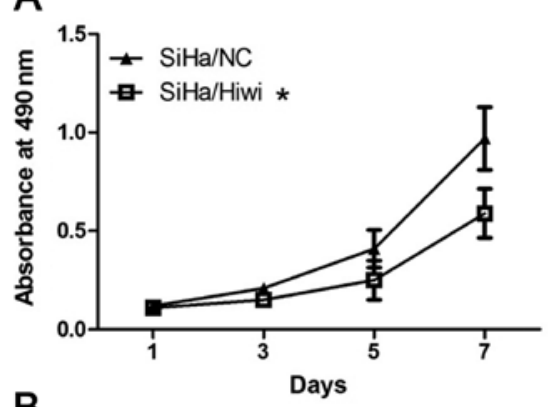

B

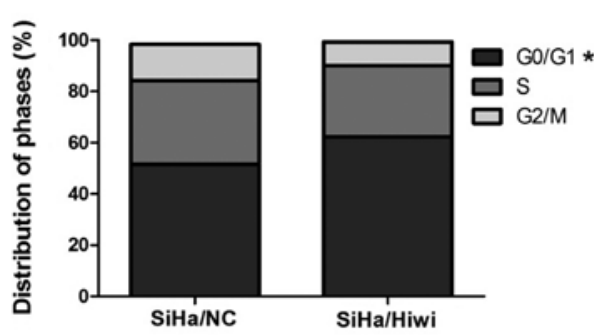

C

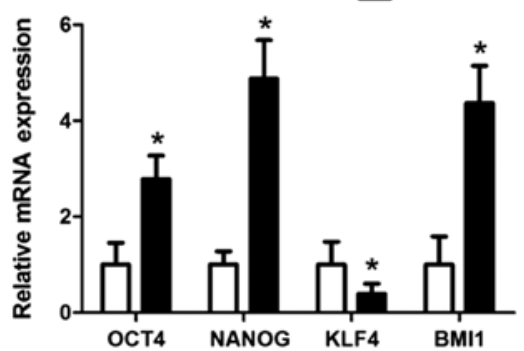

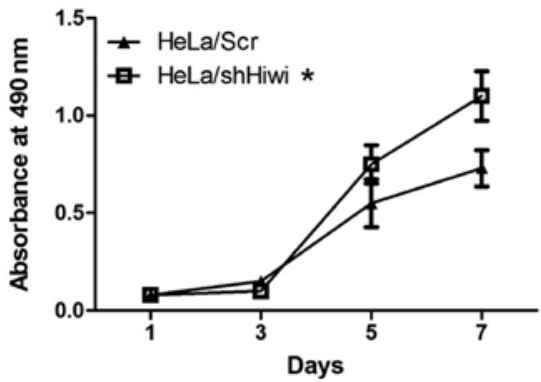
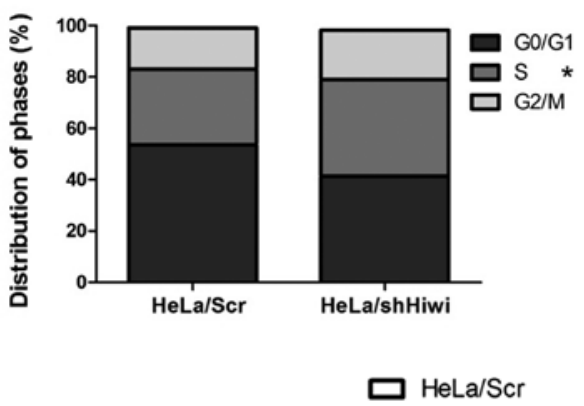

HeLa/shHiwi

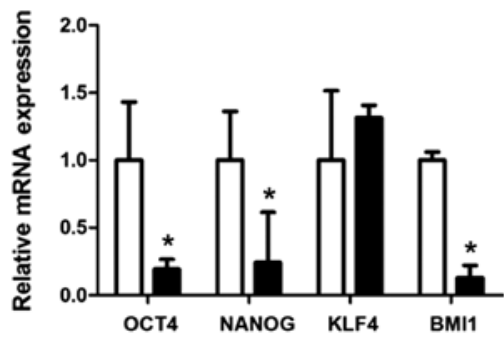

Figure 4. Hiwi induces stem cell characteristics in cervical cancer. (A) MTT assays of cell viability of SiHa (left) and HeLa (right) cells after Hiwi overexpression and silencing, respectively. ${ }^{*} \mathrm{P}<0.05$. (B) The percentages of $\mathrm{SiHa} /$ Hiwi and $\mathrm{SiHa} / \mathrm{NC}$ cells (left) and $\mathrm{HeLa} / \mathrm{shHiwi}$ and $\mathrm{HeLa} / \mathrm{Scr}$ cells (right) in the $\mathrm{G}_{0} / \mathrm{G}_{1}$, $\mathrm{S}$ and $\mathrm{G}_{2} / \mathrm{M}$ phases of the cell cycle as determined by flow cytometry. ${ }^{*} \mathrm{P}<0.05$. (C) The relative expression of stem cell-related genes $(\mathrm{OCT} 4$, NANOG, KLF4 and BMI1) in $\mathrm{SiHa}$ (left) and HeLa (right) cells as determined by real-time PCR after Hiwi overexpression and silencing, respectively. ${ }^{\mathrm{P}<0.05 .}$

of malignancy; however, no significant correlations were found between Hiwi expression and other clinical characteristics, including age and grade (Table I, $\mathrm{P}>0.05$ ).

Expression of Hiwi in cervical cancer cell lines. Endogenous Hiwi protein levels were examined by western blotting and ICC in the three cervical cancer cell lines. Immunocytochemical staining results showed that Hiwi was expressed in the three cervical cancer cell lines and no immunostaining was detected in the negative controls (Fig. 2A). The positive percentage of Hiwi expression in the SiHa, HeLa and C33A cells was 16, 39 and $61 \%$, respectively (Fig. 2B). Compared to the SiHa cells, the expression of Hiwi in the $\mathrm{C} 33 \mathrm{~A}$ and HeLa cells was higher as determined by western blot analysis (Fig. 2C).

Hiwi faciliates resistance to cisplatin in cervical cancer. To investigate the role of Hiwi in cervical carcinogenesis, we analyzed the expression of Hiwi in the response to radiotherapy and chemoradiotherapy of cervical cancers. The arrays showed that the mRNA expression of Hiwi was significantly upregulated after chemoradiotherapy when compared to the level before therapy (Fig. 3A, P<0.05), while radiotherapy did not affect Hiwi expression (Fig. 3A, P>0.05). This indicated that Hiwi may induce resistance to chemotherapy drugs. In order to investigate whether Hiwi influences the effects of chemotherapy drugs, the Hiwi-overexpression vector or a negative control vector was stably transfected in SiHa cells, and the Hiwi-specific short hairpin interference RNA vector or a scramble control vector was stably transfected in HeLa cells, respectively. The efficiencies of transfection were validated by western blot analysis (Fig. 3B). We then treated the $\mathrm{SiHa} / \mathrm{Hiwi}$ and HeLa/shHiwi cells with cisplatin (DDP), which is one of the most commonly used chemotherapeutic drugs for the treatment of cervical cancer. The effect of cisplatin (DDP) was determined by MTT assay. After a 24-h treatment at different concentrations, the viability of the $\mathrm{SiHa} /$ Hiwi cells was significantly higher than that of the SiHa/NC cells, while it was obviously lower in the HeLa/shHiwi cells when compared with that of the HeLa/Scr cells (Fig. 3C, $\mathrm{P}<0.05)$. Moreover, cell viability was also determined by MTT assay after exposure to $3 \mu \mathrm{g} / \mathrm{ml}$ cisplatin for 24,48 , or $72 \mathrm{~h}$. The viability of the $\mathrm{SiHa} / \mathrm{Hiwi}$ cells was significantly higher than that of the $\mathrm{SiHa} / \mathrm{NC}$ cells, while it was lower in the HeLa/ shHiwi cells than that in the HeLa/Scr cells (Fig. 3D, $\mathrm{P}<0.05$ ). These results demonstrated that cisplatin caused inhibition of viability in a dose-dependent and time-dependent manner in 
A
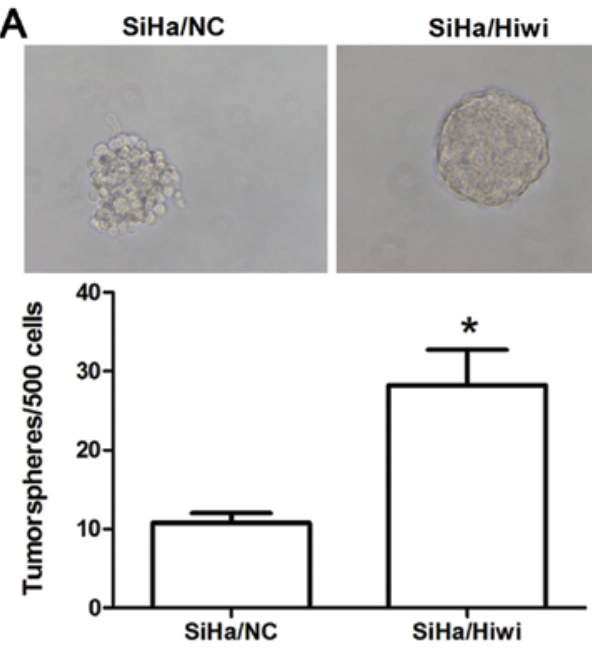

B
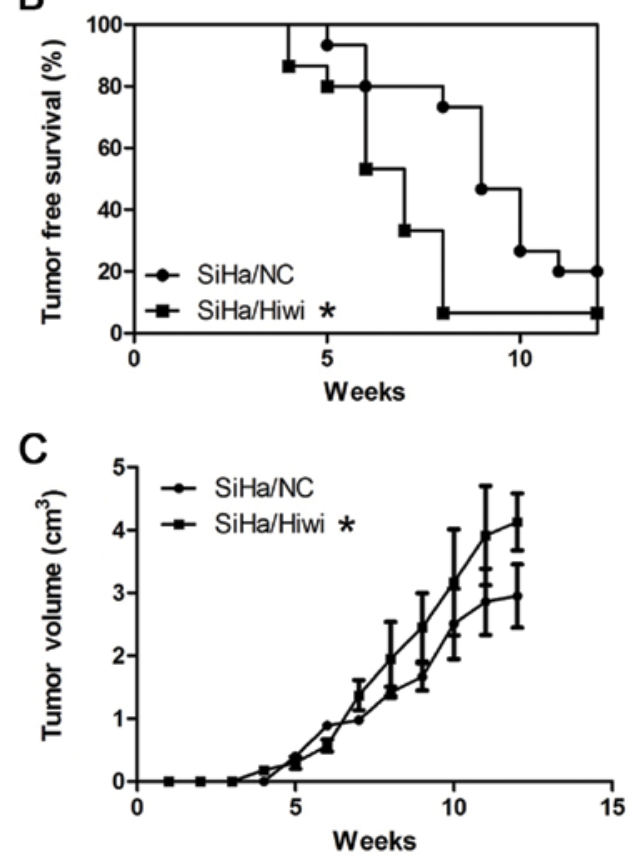

$\mathrm{SiHa/Hiwi}$
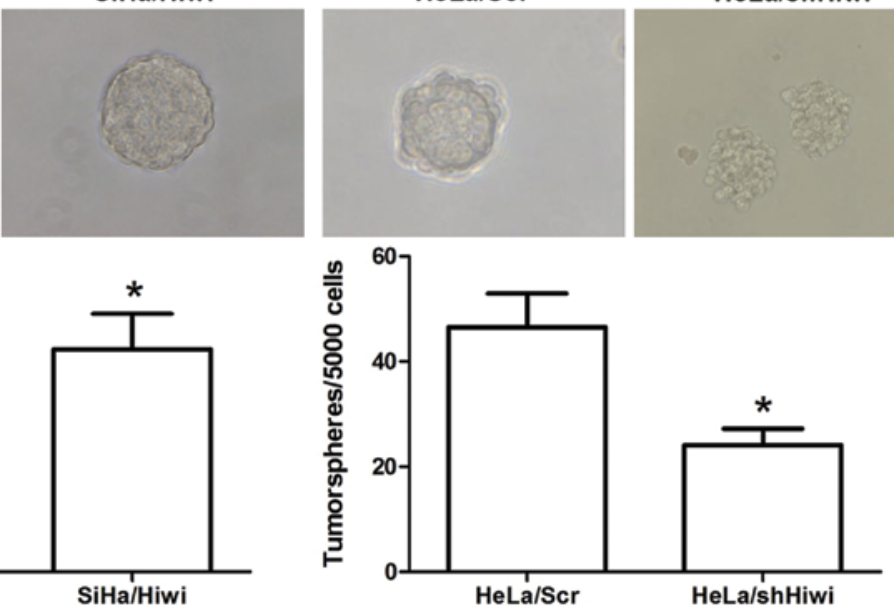
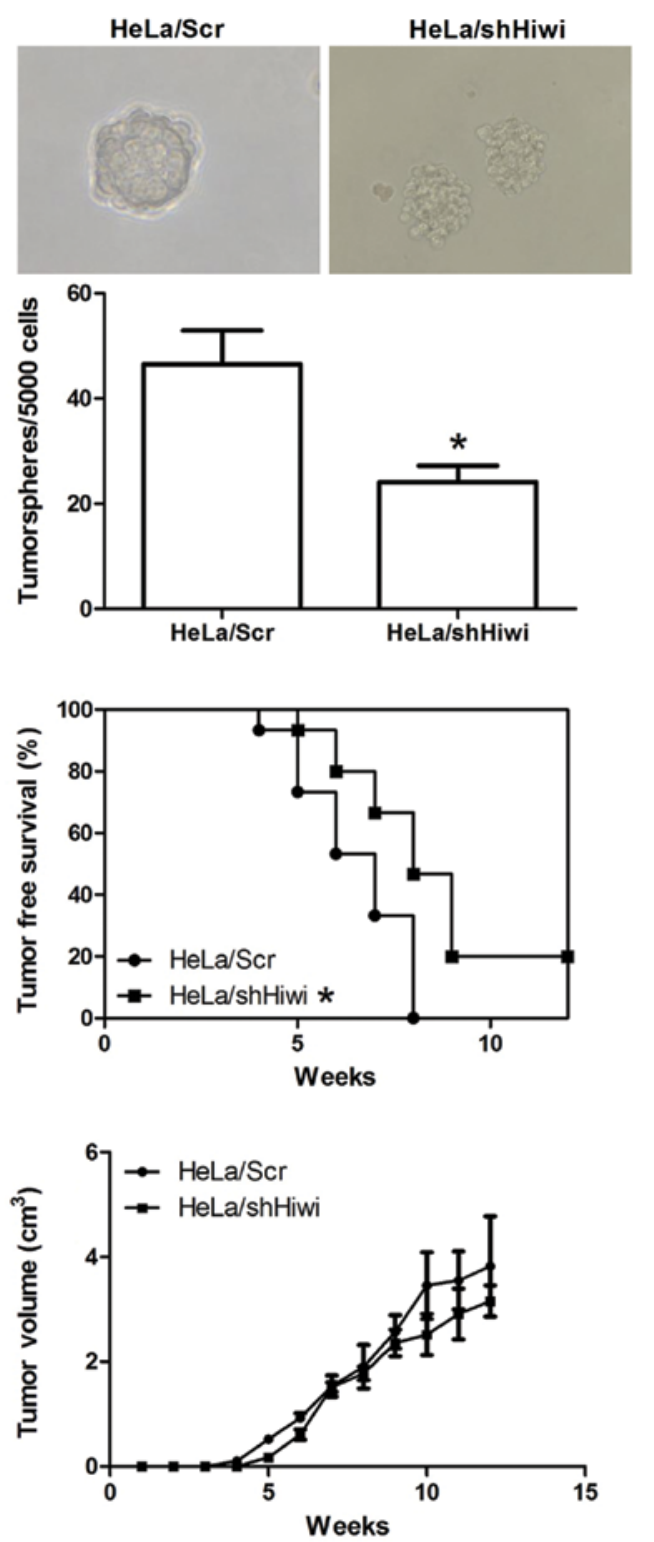

Figure 5. Hiwi promotes tumorigenicity in vitro and in vivo. (A) Tumorsphere formation assays of SiHa (left) and HeLa (right) cell lines after Hiwi overexpression or silencing, respectively. ${ }^{*} \mathrm{P}<0.05$. (B) Tumor-free survival probability and (C) tumor volume in BALB/c mice following subcutaneous injection of $\mathrm{SiHa}\left(\right.$ left) and HeLa (right) cells over time. ${ }^{*} \mathrm{P}<0.05$.

both of the SiHa and HeLa cells suggesting that Hiwi induces resistance to chemotherapy.

Hiwi induces stem cell characteristics in cervical cancer. We further investigated the effect of Hiwi on the growth and proliferation of cervical cancer. As a stem cell-associated protein, ectopic Hiwi inhibited the cell viability in SiHa cells, while silencing of Hiwi in HeLa cells significantly promoted the cell viability as determined by MTT assay (Fig. 4A, $\mathrm{P}<0.05$ ). In addition, ectopic Hiwi arrested the cell cycle at the $G_{0} / G_{1}$ phase in $\mathrm{SiHa} / \mathrm{Hiwi}$ cells $(62.3 \pm 7.36 \%)$ when compared to $\mathrm{SiHa} / \mathrm{NC}$ cells $(51.6 \pm 4.98 \%)$, while silencing of Hiwi accelerated the cell cycle into the $\mathrm{S}$ phase in the HeLa/shHiwi cells $(37.7 \pm 5.10)$

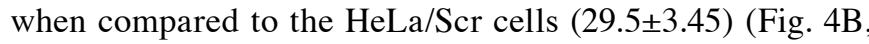
$\mathrm{P}<0.05)$. Moreover, we detected the expression of stem cellrelated transcription factors, OCT4, NANOG, KLF4 and BMI1, which are important for maintaining the self-renewal 
formed tumorspheres after a 2-week culture, but only $\sim 0.5 \%$ of $\mathrm{HeLa} / \mathrm{shHiwi}$ cells did, even when the latter were cultured up to 3 weeks.

To further confirm the potential of Hiwi in tumorigenesis in vivo, a tumor formation assay was conducted with $\mathrm{BALB} / \mathrm{c}$ nude mice. Cells began to form palpable tumors in the majority of injected mice after 4-5 weeks. Importantly, ectopic Hiwi promoted the frequency of tumor formation and inhibited the latency period of tumors derived from the SiHa cells, and silencing of Hiwi had the opposite effect (Fig. 5B, $\mathrm{P}<0.05$ ). After tumor initiation, Hiwi significantly promoted the tumor growth (Fig. 5C, $\mathrm{P}<0.05$ ). However, silencing of Hiwi did not significantly affect the xenograft growth rates (Fig. 5C, $\mathrm{P}>0.05)$.

\section{Discussion}

Hiwi, encoding a highly basic 861-amino acid protein, is a member of the Piwi family that represents the only known class of evolutionarily conserved genes that are required for stem cell function in diverse organisms $(21,22)$. Recently, increasing evidence suggests that dysregulation of Hiwi is associated with the pathogenesis of several human cancers (14,23-25).

In this study, we determined the expression of Hiwi in normal and pathologic cervical tissues, as well as in cervical cancer cell lines. IHC showed a higher level of Hiwi expression in high-grade squamous intraepithelial lesions (HSILs) and cervical cancers (CCs) than that in normal cervix (NC) (Fig. 1), and a positive relationship with pathological stage (Table I), which indicates that Hiwi expression may be associated with cervical carcinogenesis. This finding is of great importance as Hiwi expression was found in the basal cells of normal cervical tissues where epithelial reserve cells are located. Reserve cells are likely candidates for cervical stem cells (26). These results are similar to previous studies that found that Hiwi has functions in the maintenance of stem cells and cancer stem cells $(8,13,27)$, suggesting that Hiwi participates in the physiological function of the cervix and may be involved in cervical carcinogenesis as a cancer stem marker.

On the basis of this hypothesis, we analyzed Hiwi expression in the response of cervical cancer to radiotherapy alone or radiotherapy plus concomitant chemotherapy with cisplatin, since chemical resistance is one of the characteristics of CSCs. The array dataset showed that Hiwi was upregulated after chemoradiotherapy, suggesting that Hiwi is associated with cisplatin resistance. Thus, overexpression and silencing of Hiwi were induced in SiHa and HeLa cells, respectively, for further investigation. The MTT assays demonstrated that cisplatin caused dose-dependent and time-dependent inhibition of viability in both of the SiHa and HeLa cells suggesting that Hiwi induced resistance to chemotherapy (Fig. 3).

In addition, we observed that ectopic Hiwi inhibited the growth and proliferation of SiHa cells while the silencing of Hiwi promoted these abilities in HeLa cells (Fig. 4). This result suggests that Hiwi induces a stemness characteristic in cervical cancer as stem cells exhibit a quiescent state. Furthermore, the mechanism of cisplatin resistance has been previously proposed. Cisplatin is a nonspecific drug which acts on the cell cycle in several types of cancers, inhibiting DNA synthesis by binding to and causing crosslinking of DNA, which ultimately triggers apoptosis (28). Hiwi-induced cisplatin resistance may be due to cell cycle arrest.

Apart from chemical resistance, cancer stem cells are characterized by two other common properties: self-renewal and tumorigenesis $(29,30)$. Thus, we detected several selfrenewal-related transcription factors and found that Hiwi facilitates expression of these markers, indicating a stemness signature. Moreover, the tumorsphere formation assay showed larger tumorspheres and a higher percentage of formation in the $\mathrm{SiHa} / \mathrm{Hiwi}$ and $\mathrm{HeLa} / \mathrm{Scr}$ cells than these parameters in the $\mathrm{SiHa} / \mathrm{NC}$ or HeLa/shHiwi cells, while the tumor xenograft experiment showed a reduced tumor-free period and a lower tumor-free rate in mice injected with the $\mathrm{SiHa} / \mathrm{Hiwi}$ and $\mathrm{HeLa} / \mathrm{Scr}$ cells than in mice injected with the $\mathrm{SiHa} / \mathrm{NC}$ or HeLa/shHiwi cells (Fig. 5), demonstrating that Hiwi promotes cells to possess a higher tumor-initiating capacity in vitro and in vivo.

In summary, the present study elucidated the role of Hiwi expression in cervical cancers. Cells expressing Hiwi exhibited resistance to chemotherapy drugs and increased tumorigenesis in vitro and in vivo. Additionally, these cells possessed the ability for self-renewal and expressed high levels of stem cellrelated transcription factors. Based on this study, Hiwi may be considered as a marker for cervical CSCs, and a target with which to explore novel strategies for the diagnosis, prognosis and therapy of cervical cancer.

\section{Acknowledgements}

This project was supported by the National Natural Science Foundation of China (no. 81270435).

\section{References}

1. Jemal A, Bray F, Center MM, Ferlay J, Ward E and Forman D: Global cancer statistics. CA Cancer J Clin 61: 69-90, 2011.

2. Reid R: Genital warts and cervical cancer. II. Is human papillomavirus infection the trigger to cervical carcinogenesis? Gynecol Oncol 15: 239-252, 1983.

3. Burd EM: Human papillomavirus and cervical cancer. Clin Microbiol Rev 16: 1-17, 2003.

4. Clarke MF, Dick JE, Dirks PB, et al: Cancer stem cells perspectives on current status and future directions: AACR Workshop on cancer stem cells. Cancer Res 66: 9339-9344, 2006.

5. Visvader JE and Lindeman GJ: Cancer stem cells in solid tumours: accumulating evidence and unresolved questions. Nat Rev Cancer 8: 755-768, 2008

6. Lingel A and Sattler M: Novel modes of protein - RNA recognition in the RNAi pathway. Curr Opin Struct Biol 15: 107-115, 2005.

7. Cox DN, Chao A, Baker J, Chang L, Qiao D and Lin H: A novel class of evolutionarily conserved genes defined by piwi are essential for stem cell self-renewal. Genes Dev 12: 3715-3727, 1998.

8. Grochola LF, Greither T, Taubert H, et al: The stem cell-associated Hiwi gene in human adenocarcinoma of the pancreas: expression and risk of tumour-related death. Br J Cancer 99: 1083-1088, 2008.

9. Qiao D, Zeeman AM, Deng W, Looijenga LH and Lin H: Molecular characterization of hiwi, a human member of the piwi gene family whose overexpression is correlated to seminomas. Oncogene 21: 3988-3999, 2002.

10. Liu X, Sun Y, Guo J, et al: Expression of hiwi gene in human gastric cancer was associated with proliferation of cancer cells. Int J Cancer 118: 1922-1929, 2006.

11. Taubert H, Greither T, Kaushal D, et al: Expression of the stem cell self-renewal gene Hiwi and risk of tumour-related death in patients with soft-tissue sarcoma. Oncogene 26: 1098-1100, 2007. 
12. Taubert H, Würl P, Greither T, et al: Stem cell-associated genes are extremely poor prognostic factors for soft-tissue sarcoma patients. Oncogene 26: 7170-7174, 2007.

13. Sharma AK, Nelson MC, Brandt JE, et al: Human CD34(+) stem cells express the hiwi gene, a human homologue of the Drosophila gene piwi. Blood 97: 426-434, 2001.

14. Siddiqi S, Terry M and Matushansky I: Hiwi mediated tumorigenesis is associated with DNA hypermethylation. PLoS One 7: e33711, 2012.

15. Gao Q, Liu W, Cai J, et al: EphB2 promotes cervical cancer progression by inducing epithelial-mesenchymal transition. Hum Pathol 45: 372-381, 2014.

16. Iwakawa M, Ohno T, Imadome $\mathrm{K}$, et al: The radiation-induced cell-death signaling pathway is activated by concurrent use of cisplatin in sequential biopsy specimens from patients with cervical cancer. Cancer Biol Ther 6: 905-911, 2007.

17. Ji J and Zheng PS: Expression of Sox 2 in human cervical carcinogenesis. Hum Pathol 41: 1438-1447, 2010.

18. Zhang Y, Li B, Ji ZZ and Zheng PS: Notch1 regulates the growth of human colon cancers. Cancer 15: 5207-5218, 2010.

19. Singh SK, Clarke ID, Terasaki M, et al: Identification of a cancer stem cell in human brain tumors. Cancer Res 63: 5821-5828, 2003.

20. Ponti D, Costa A, Zaffaroni N, et al: Isolation and in vitro propagation of tumorigenic breast cancer cells with stem/progenitor cell properties. Cancer Res 65: 5506-5511, 2005.

21. Benfey PN: Stem cells: A tale of two kingdoms. Curr Biol 9: R171-R172, 1999.
22. Cox DN, Chao A and Lin H: piwi encodes a nucleoplasmic factor whose activity modulates the number and division rate of germline stem cells. Development 127: 503-514, 2000.

23. Sun G, Wang Y, Sun L, et al: Clinical significance of Hiwi gene expression in gliomas. Brain Res 1373: 183-188, 2011.

24. Liu C, Qu L, Dong B, et al: Combined phenotype of 4 markers improves prognostic value of patients with colon cancer. Am J Med Sci 343: 295-302, 2012.

25. Liu WK, Jiang XY and Zhang ZX: Expression of PSCA, PIWIL1 and TBX2 and its correlation with HPV16 infection in formalinfixed, paraffin-embedded cervical squamous cell carcinoma specimens. Arch Virol 155: 657-663, 2010.

26. Peters WM: Nature of 'basal' and 'reserve' cells in oviductal and cervical epithelium in man. J Clin Pathol 39: 306-312, 1986.

27. Liang D, Yang Y and Liu Y: The role Hiwi gene in the maintenance of lung cancer stem cell populations. Neoplasma: Dec 4, 2013 (Epub ahead of print). doi: 10.4149/neo_2014_022.

28. Stordal B, Pavlakis N and Davey R: A systematic review of platinum and taxane resistance from bench to clinic: an inverse relationship. Cancer Treat Rev 33: 688-703, 2007.

29. Lin H: The tao of stem cells in the germline. Annu Rev Genet 31: 455-491, 1997.

30. Podberezin M, Wen J and Chang CC: Cancer stem cells: a review of potential clinical applications. Arch Pathol Lab Med 137: 1111-1116, 2013. 